\title{
A cytochemical method for measuring enzyme activity in individual preovulatory mouse oocytes
}

\author{
G. G. De Schepper, C. J. F. Van Noorden* and F. Koperdraad \\ Institute of Human Genetics, and * Laboratory for Histology and Cell Biology, Academic Medical \\ Center, Meibergdreef 15, $1105 \mathrm{AZ}$ Amsterdam, The Netherlands
}

\begin{abstract}
Summary. The activities of 6 enzymes involved in carbohydrate metabolism were determined quantitatively in preovulatory oocytes by cytochemical means per individual cell as well as biochemically in cell homogenates. Oocytes were incorporated in a polyacrylamide matrix for appropriate enzyme cytochemical staining. This incorporation preserves the morphology of the cells very well, and the enzymes keep their activity for a considerable period of time. This method could also be used to demonstrate more than one enzyme activity in the same cell. The results obtained by cytochemical means appeared to correlate very well with the biochemical data $(P<$ 0.005 ). Glucose 6-phosphate dehydrogenase, the key-enzyme in the pentose phosphate pathway, had very high activity in these preovulatory oocytes, but 6-phosphogluconate dehydrogenase activity was only about $2 \%$ of that of glucose 6-phosphate dehydrogenase. The activities of lactate dehydrogenase and to a lesser extent glucose phosphate isomerase and D-glyceraldehyde-3-phosphate dehydrogenase also appeared to be very high, while hexokinase showed a very low activity.
\end{abstract}

\section{Introduction}

In-vitro maturation of preovulatory mouse oocytes and development of preimplantation mouse embryos from the one-cell stage up to the blastocyst can take place in a basic salt solution with pyruvate as the only energy source (Brinster, 1965a). Furthermore, in-vitro maturation of preovulatory oocytes with glucose as the energy substrate instead of pyruvate will not occur in the absence of follicular cells. These cells produce pyruvate from glucose and supply it to the oocytes (Donahue \& Stern, 1968). These findings indicate that carbohydrate metabolism in mammalian oocytes and in preimplantation embryos is unique in comparison with that in more differentiated cells. Understanding of the energy metabolism of these cells is most important, especially in view of the technique of in-vitro fertilization and implantation in man.

Since Brinster (1965b) published a study of lactate dehydrogenase activity in the preimplantation mouse embryo, biochemical studies of enzyme activities in homogenates of mouse oocytes and preimplantation embryos have resulted in quantitative information of the activity of about 15 different enzymes (Epstein, 1975). However, the use of homogenates has several disadvantages, e.g. disruption of the cells which averages the data per cell and gives no information about the localization of enzyme activity. Therefore, determination of enzyme activities with cytochemical staining methods at the single cell level may solve these problems in metabolic studies of individual oocytes. On the other hand, practical difficulties are also to be expected with enzyme cytochemical methods when cells are stained in smears or in suspension, and these include loss of cells, disruption of cell membranes or entire destruction of low enzyme activities by fixation. Also, leakage of enzyme molecules and/or (coloured) reaction products out of the cells may occur, preventing discrimination between activities of individual cells in a population (Stuart, Gordon \& Lee, 1975). 
Van Noorden, Tas, Vogels \& De Schepper (1982) have described a new method for the demonstration of enzyme activity in individual cells after trapping them in a polyacrylamide matrix. This method solves at least some of the problems occurring with enzyme cytochemistry of individual cells: quantitative data can be obtained using this method for the determination of glucose 6-phosphate dehydrogenase activity in individual isolated rat hepatocytes (Van Noorden, Tas \& Vogels, 1983) and in isolated mouse oocytes (De Schepper, Van Noorden, Tas \& James, 1982; De Schepper, Van Noorden \& James, 1984). In the present study, this cytochemical method has been applied for the analysis of activities of 6 enzymes involved in carbohydrate metabolism in fully grown preovulatory oocytes. The cytochemical data have been correlated with data obtained with parallel biochemical studies.

\section{Materials and Methods}

\section{Oocyte recovery}

Preovulatory oocytes were obtained from Swiss mice ( $\mathrm{Cpb}: \mathrm{SE}, \mathrm{TNO}$, The Netherlands), 8-12 weeks of age. The animals were killed by cervical dislocation. Ovaries were rapidly removed and freed from adhering tissue in $100 \mathrm{~mm}$-phosphate buffer $(\mathrm{pH} 7 \cdot 4)$ in the presence of $0.1 \%(\mathrm{w} / \mathrm{v})$ polyvinyl pyrrolidone (PVP buffer; Sigma, St Louis, MO, U.S.A.). Oocytes were isolated by puncturing large antral follicles with a 25 -gauge needle. Oocytes with an intact germinal vesicle, free from follicular cells and with a diameter of $85-100 \mu \mathrm{m}$ were selected, presuming that these oocytes are close to full maturation (Mangia \& Epstein, 1975). The isolated oocytes were collected in a drop of fresh PVP buffer and rinsed twice. For biochemical studies 20-50 oocytes were frozen $\left(-70^{\circ} \mathrm{C}\right)$ in $25 \mu 1100 \mathrm{~mm}$-phosphate buffer $\left(\mathrm{pH} \mathrm{7.4)}\right.$ and stored at $-70^{\circ} \mathrm{C}$ until activities were determined (within 3 days). For cytochemical studies, oocytes were processed immediately after isolation.

\section{Enzyme cytochemistry}

Incorporation of oocytes in a polyacrylamide gel. Isolated oocytes were fixed in $0 \cdot 1 \%$ glutaraldehyde in PVP buffer $\left(5 \mathrm{~min}, 4^{\circ} \mathrm{C}\right)$ in the presence of $20 \mathrm{mM}-\mathrm{NADP}^{+}$or $\mathrm{NAD}^{+}$ (Boehringer, Mannheim, West Germany) to protect the active sites of some enzymes particularly sensitive to fixation (Van Noorden et al., 1982, 1983). After fixation, the cells were rapidly rinsed 3 times and mixed with a $12 \%(\mathrm{w} / \mathrm{v})$ monomeric acrylamide mixture (Serva, Heidelberg, West Germany) according to De Schepper et al. (1984). In between, the oocytes were preincubated in a buffered solution of $20 \mathrm{~mm}-\mathrm{NADP}^{+}$or $\mathrm{NAD}^{+}\left(5 \mathrm{~min}, 4^{\circ} \mathrm{C}\right)$ to protect the activity of some dehydrogenases against the detrimental effect of polymerization (Van Noorden et al., 1982).

Polymerization took place between glass plates with an intervening space of $195 \mu \mathrm{m}$ under u.v. radiation $\left(366 \mathrm{~nm}, 60 \mathrm{~min}, 4^{\circ} \mathrm{C}\right)$. The glass plates were reversed every $10 \mathrm{~min}$ to prevent sedimentation of the large oocytes on the lower glass plate which appeared to lead to loss of cells due to incomplete incorporation. After polymerization, the gels with incorporated oocytes were washed three times for $10 \mathrm{~min}$ with $100 \mathrm{mM}$-phosphate buffer ( $\mathrm{pH} \mathrm{7.4).} \mathrm{Incubations} \mathrm{for} \mathrm{enzyme} \mathrm{activities}$ were carried out immediately after the washing procedure, except in one case when cytochemical staining for glucose 6-phosphate dehydrogenase (G6PDH) was performed after storage for $24 \mathrm{~h}$ in buffer at $4^{\circ} \mathrm{C}$.

Enzyme cytochemical procedures. Incorporated preovulatory oocytes were stained for the activity of 6 different enzymes with the use of tetranitro blue tetrazolium (TNBT: Serva) as final electron acceptor, because all enzymes were assayed by coupling with enzymes which require $\mathrm{NAD}^{+}$or $\mathrm{NADP}^{+}$as coenzymes. 1-Methoxyphenazine methosulphate (1-methoxyPMS; Dojindo, Kumamoto, Japan) was used as intermediate electron carrier; it transfers directly all electrons from NADPH or NADH to the tetrazolium salt (Van Noorden \& Tas, 1982a, b). The incubation media 
for the various enzyme assays are summarized in Table 1. Control experiments were carried out in the absence of substrate. The activity of glucose phosphate isomerase was also determined by using $0.2,0.4$ and $0.5 \mathrm{~mm}$-fructose 6-phosphate in the presence of $0,1,2,4,5,8$ or $10 \mathrm{~mm}-6-$ phosphogluconate, a competitive inhibitor of glucose phosphate isomerase activity (Rose \& Rose, 1969). After incubation, the films were rinsed overnight at $4^{\circ} \mathrm{C}$ in phosphate buffer (pH 5.3) to remove unreduced TNBT. They were stored at $4^{\circ} \mathrm{C}$ until cytophotometric analysis in the same buffer to which a crystal of thymol was added.

Some oocytes in polyacrylamide films were cut into two parts with a razor blade before being stained and they were incubated for G6PDH activity after the washing procedures. One part of the gels was incubated in the presence of substrate and the other part in the absence of substrate.

In some experiments, oocytes fixed in $0.1 \%$ glutaraldehyde were collected in a watchglass, frozen in liquid nitrogen and thawed at room temperature. The frozen-thawed oocytes were incubated for the demonstration of G6PDH activity in the presence and absence of glucose 6phosphate as substrate $\left(15 \mathrm{~min}, 25^{\circ} \mathrm{C}\right)$. Oocytes not being stained after the period of incubation were incorporated in a polyacrylamide matrix as described earlier. After incorporation, these oocytes were then again incubated in the presence or absence of glucose 6-phosphate.

Cytophotometry of enzyme activities. Gels with incorporated oocytes stained for enzyme activity in the presence or absence of substrate were brought onto glass slides and mounted in distilled water. The integrated absorbance of the formazan precipitated in individual oocytes was measured with a scanning and integrating cytophotometer as described by James, Tas, Bosch, De Meere \& Schuyt (1979), using a $\times 20$ (N.A. 0.45) achromatic lens (Olympus) as condenser with a Wild

Table 1. Composition of media used for enzyme cytochemical incubation of isolated oocytes (the components are listed in $\mathrm{mM}$ as dissolved in $100 \mathrm{~mm}$-phosphate buffer $\mathrm{pH} 7.4$ )

\begin{tabular}{|c|c|c|c|c|c|c|}
\hline \multirow[b]{2}{*}{ Compound* } & \multicolumn{6}{|c|}{ Enzyme† } \\
\hline & Hexokinase & G6PDH & GPI & G3PDH & LDH & $6 \mathrm{PGDH}$ \\
\hline NADP+ & 0.48 & 0.48 & 0.48 & - & - & 0.48 \\
\hline $\mathrm{NAD}^{+}$ & - & - & - & 0.48 & 0.48 & - \\
\hline $\mathrm{MgCl}_{2}$ & $4 \cdot 00$ & 4.00 & 4.00 & - & 4.00 & $4 \cdot 00$ \\
\hline $\mathrm{NaN}_{3}$ & $5 \cdot 00$ & 5.00 & $5 \cdot 00$ & $5 \cdot 00$ & $5 \cdot 00$ & $5 \cdot 00$ \\
\hline Amylobarbitone & $2 \cdot 30$ & $2 \cdot 30$ & $2 \cdot 30$ & $2 \cdot 30$ & $.2 \cdot 30$ & $2 \cdot 30$ \\
\hline mPMS & $0 \cdot 10$ & $0 \cdot 10$ & $0 \cdot 10$ & $0 \cdot 10$ & $0 \cdot 10$ & $0 \cdot 10$ \\
\hline TNBT & 1.00 & 1.00 & 1.00 & 1.00 & 1.00 & 1.00 \\
\hline ATP & $1 \cdot 20$ & - & - & - & - & - \\
\hline Glucose & 0.67 & - & - & - & - & - \\
\hline G6P & - & 0.67 & - & - & - & - \\
\hline F6P & - & - & 0.67 & - & - & - \\
\hline G3P & - & - & - & $2 \cdot 30$ & - & - \\
\hline Sodium lactate & - & - & - & - & 100 & - \\
\hline 6PG & - & - & - & - & - & 0.67 \\
\hline Temp. $\left({ }^{\circ} \mathrm{C}\right)$ & 37 & 25 & 25 & 37 & 25 & 37 \\
\hline Incubation time (min) & 60 & 5 & 5 & 60 & 5 & 60 \\
\hline
\end{tabular}

* NADP, disodium salt; NAD, free acid; F6P, fructose 6-phosphate disodium salt; ATP, adenosine-5'triphosphate cryst. disodium salt, special quality; G3P, glyceraldehyde-3-phosphate hydrolysed from Dglycerinaldehyde-3-phosphate-diethylacetal (Boehringer, Mannheim, West Germany): TNBT, tetranitro blue tetrazolium; G6P, D-glucose 6-phosphate disodium salt; 6PG, 6-phosphogluconic acid trisodium salt; amylobarbitone (Amytal) (Serva, Heidelberg, West Germany): sodium lactate; $\mathbf{M g C l}_{2}$ (BDH, U.K.): $\mathbf{N a N}_{3}$ (Sigma); glucose (Merck, Darmstadt, West Germany): mPMS, 1-methoxy phenazine methosulphate (Dojindo, Kumamoto, Japan).

$\dagger$ Hexokinase (EC 2.7.1.1); G6PDH, glucose 6-phosphate dehydrogenase (EC 1.1.1.49); GPI, glucosephosphate isomerase (EC 5.3.1.9); G3PDH, glyceraldehyde-3-phosphate dehydrogenase (EC 1.2.1.12); LDH, lactate dehydrogenase (EC 1.1.1.27); 6PGDH, 6-phosphogluconate dehydrogenase (decarboxylating, EC 1.1.1.44). 
precision mechanical stage. The readings were taken with a Leitz planachromatic objective $\times 6.3$ (N.A. 0.20) using an interference filter of $534 \mathrm{~nm}$ (Barr and Stroud, Glasgow, U.K.) as described by Van Noorden et al. (1983). The mean value of the integrated absorbance of oocytes incubated in the absence of substrate was subtracted from that of oocytes incubated in the presence of substrate.

\section{Biochemical enzyme assays}

All enzyme activities were basically determined according to Yasumasu, Fujiwara, Shoger \& Asami (1975), with the exception of G3PDH and 6PGDH activities, which were measured as described by Beutler (1971). The reaction mixture contained 100 mM-PVP buffer (pH 7.4); concentrations of coenzymes and substrates as well as the temperature were similar to those in the cytochemical media (Table 1). The auxiliary enzymes used were from Boehringer. The total volume for each assay was $400 \mu$ l. Activities were determined by measuring the increase or decrease in absorbance during $40 \mathrm{~min}$ at $340 \mathrm{~nm}$ with a Zeiss M4 QIII spectrophotometer.

\section{Results}

The morphology of the oocytes after incorporation in a polyacrylamide gel matrix and staining for G6PDH activity is well-preserved and the formazan precipitation is limited to the cytoplasm, leaving the zona pellucida unstained (PI. 1, Figs 1 \& 2). Leakage of formazan from the cells could not be detected. When incorporated oocytes cut into two parts were stained for G6PDH activity, it appeared that virtually no cellular constituents were washed out of the cells (P1. 1, Fig. 3).

No significant difference $(P<0.005)$ could be detected between incorporated oocytes incubated for G6PDH activity after rinsing for $30 \mathrm{~min}$ at $4^{\circ} \mathrm{C}(\Sigma \mathrm{A} 534 / 5 \mathrm{~min} /$ oocyte $=2937 \pm 128$; $n=7)$ and those incubated after rinsing for $24 \mathrm{~h}$ at $4^{\circ} \mathrm{C}(\Sigma \mathrm{A} 534 / 5 \mathrm{~min} /$ oocyte $=2850 \pm 158 ; n=$ 7). Therefore, it may be concluded that enzyme activity is kept without substantial loss for at least $24 \mathrm{~h}$ after incorporation.

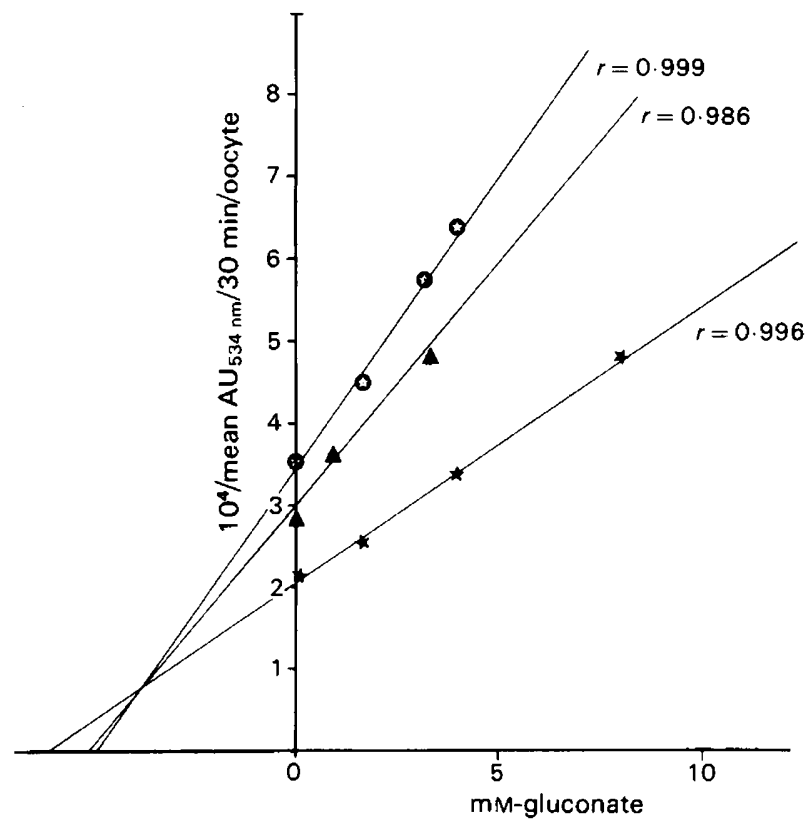

Text-fig. 1. Dixon plot of GPI activity in isolated mouse oocytes in the presence of inhibitor, 6phosphogluconate, as determined cytochemically. $r=$ coefficient of correlation. $\theta=0.2 \mathrm{mM}$ $\mathrm{F} 6 \mathrm{P} ; \boldsymbol{\Delta}=0.4 \mathrm{mM}-\mathrm{F} 6 \mathrm{P} ; \star=0.5 \mathrm{mM}-\mathrm{F} 6 \mathrm{P}$. 


\section{PLATE 1}
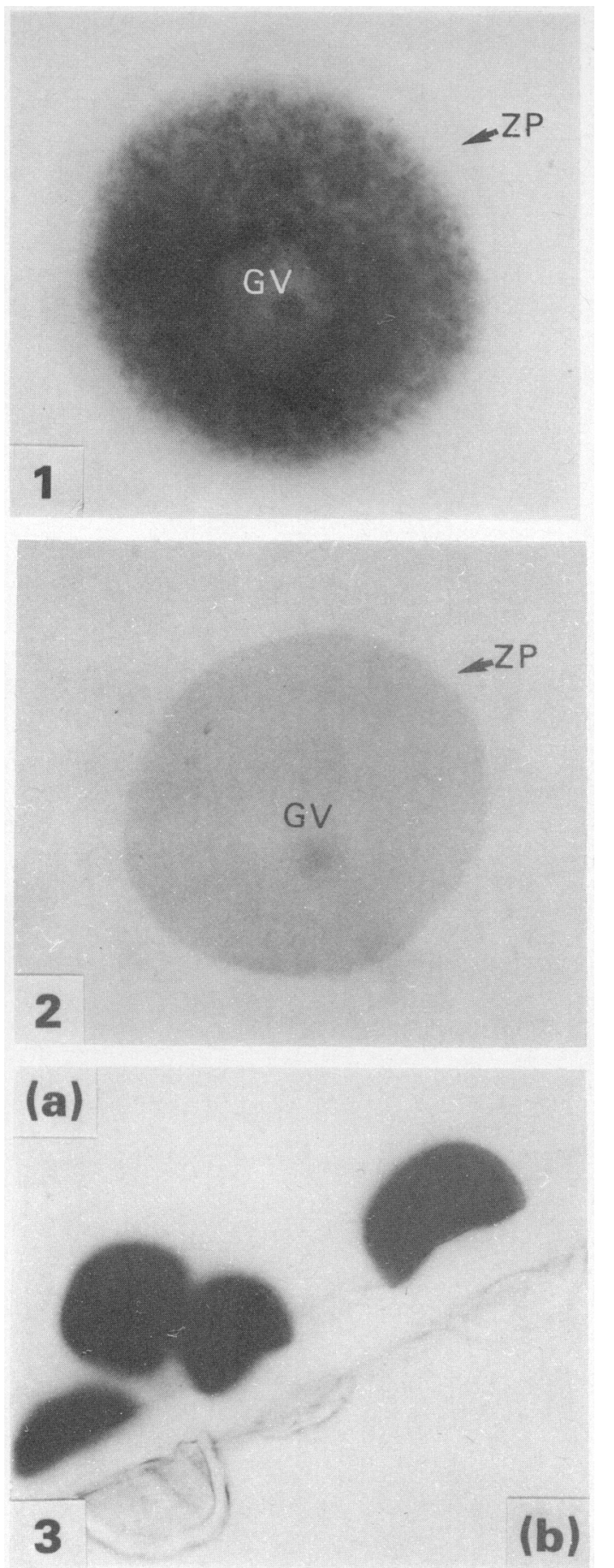

Figs 1 \& 2. Preovulatory oocytes stained for G6PDH activity after incorporation in polyacrylamide gel in the presence (Fig. 1) or absence (Fig. 2) of substrate. GV = germinal vesicle; $Z P=$ zona pellucida.

Fig. 3. Preovulatory oocytes cut after incorporation into polyacrylamide gel stained for G6PDH activity in the presence (part a) or absence (part b) of substrate. 
Table 2. Mean enzyme activity per individual oocyte \pm s.e.m. (no. of observations in parentheses) as determined with biochemical and cytochemical assays

\begin{tabular}{lcc}
\hline Enzyme* & $\begin{array}{c}\text { Biochemical assay } \\
\text { (pmol NAD(P) } \\
\text { reduced/h/oocyte) }\end{array}$ & $\begin{array}{c}\text { Cytochemical assay } \\
\text { (arbitrary units/ } \\
\text { h/oocyte) }\end{array}$ \\
\hline Hexokinase & $18 \cdot 8 \pm 2 \cdot 1(3)$ & $37 \pm 21(17)$ \\
G6PDH & $1430 \pm 70(3)$ & $16520 \pm 360(190)$ \\
GPI & $410 \pm 30(4)$ & $5792 \pm 216(181)$ \\
G3PDH & $97 \cdot 1 \pm 7 \cdot 2(2)$ & $1852 \pm 55(21)$ \\
6PGDH & $38 \cdot 6 \pm 3 \cdot 4(3)$ & $343 \pm 18(25)$ \\
LDH & $3910 \pm 30(3)$ & $39192 \pm 96(13)$ \\
\hline
\end{tabular}

* For abbreviations see Table 1 .

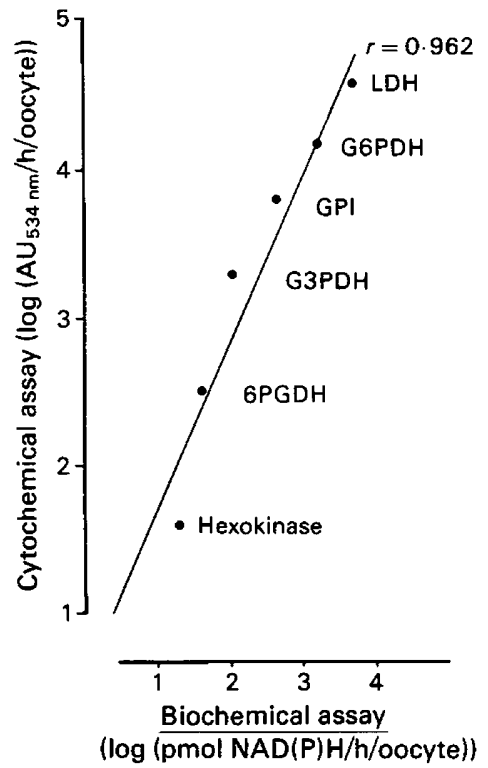

Text-fig. 2. Correlation between the mean enzyme activity in preovulatory oocytes, plotted on the basis of biochemical and cytochemical determinations. $r=$ coefficient of correlation.

G6PDH activity was also demonstrated cytochemically in oocytes which had not been incorporated in a polyacrylamide matrix. The formazan production in the presence of glucose 6phosphate appeared to be rather low in cells fixed in a solution of $0.1 \%$ glutaraldehyde and not having been subject to freezing. When the cells were fixed and frozen-thawed once, most of the cells showed a high content of formazan after cytochemical incubation for G6PDH activity, but a considerable number of cells did not stain at all. When these unstained cells were collected and incorporated in a polyacrylamide gel and stained, formazan production occurred after incubation in the presence of glucose 6-phosphate, whereas the amount did not differ significantly from that incorporated immediately after isolation without freeze-thawing. Text-figure 1 shows the relationship between the concentration of 6-phosphogluconate and the reciprocal reaction velocity of GPI activity as determined cytochemically in incorporated mouse oocytes with different concentrations of substrate. This Dixon plot demonstrates that 6-phosphogluconate behaves as a 
competitive inhibitor of GPI activity in this cytochemical assay. The $K_{\mathrm{i}}$ of this inhibition effect was $4.6 \mathrm{mM}$. The $K_{\mathrm{m}}$ of the cytochemical assay of GPI activity appeared to be $0.25 \mathrm{~mm}$.

Table 2 summarizes the results of the parallel quantitative biochemical and cytochemical assays for the enzyme activities. LDH activity was determined biochemically in two different ways, because this enzyme can only be demonstrated cytochemically when reducing $\mathrm{NAD}^{+}$. The enzyme showed an activity 10 times as high with pyruvate as substrate and NADH as coenzyme in comparison with the activity observed when sodium lactate was used as substrate and $\mathrm{NAD}^{+}$as the coenzyme $(42380 \pm 3680(n=2)$ pmol NADH oxidized/h/oocyte versus $3910 \pm 30(n=2)$ pmol $\mathrm{NAD}^{+}$reduced/h/oocyte). The data obtained biochemically and cytochemically for the different enzyme activities are compared in Text-fig. 2. A high degree of correlation appeared to exist between the values obtained by cytochemical and biochemical means $(r=0.962 ; P<0.005)$.

\section{Discussion}

The presence of the thick and resistant zona pellucida around oocytes has given rise to great difficulties in preparing smears of these large cells. So far, this seems to have prevented the use of quantitative enzyme cytochemical methods for analysis of oocyte metabolism. However, incorporation of oocytes in a polyacrylamide gel matrix has proved to be useful for the study of enzyme activities in isolated oocytes. The results reported in this study confirm previous findings (Van Noorden et al., 1982, 1983; De Schepper et al., 1982, 1984; Van Noorden \& Tas, 1982b) that, when a polyacrylamide matrix is used for enzyme cytochemical methods, no leakage of enzyme molecules, reduced intermediates, or formazan seems to occur, as formazan has never been found in the incubation medium or precipitated in the polyacrylamide matrix outside the cells (Pl. 1, Figs $1 \& 2)$. The 'nothing dehydrogenase' activity can also be kept very low with this method when incubation is made in the absence of substrate and the morphology of incorporated cells is well preserved after staining for enzyme activity. Van Noorden \& Tas (1980) have described some loss of G6PDH activity during the polymerization procedure, which can be minimized by protecting the enzymic active site with NADP+ (Van Noorden et al., 1982). From this study it may be concluded that, after the polymerization has been completed, no further loss of activity is found, at least for G6PDH and for upto $24 \mathrm{~h}$ of storage at $4^{\circ} \mathrm{C}$.

The experiment in which different parts of incorporated oocytes were stained for G6PDH activity under different conditions (Pl. 1, Fig. 3) shows that the polymerization has also taken place within the cells. Apparently, the polyacrylamide matrix can be considered as a mechanical support for the cell structures and no leakage of cellular compounds occurs with cut cells even after thoroughly rinsing for $30 \mathrm{~min}$. Incubation of parts of oocytes for G6PDH activity in the presence of substrate resulted in formazan production similar to that when fully intact incorporated oocytes were incubated. Cutting of incorporated oocytes makes it possible to investigate more than one enzyme in one and the same cell or to incubate different parts of one cell under various conditions.

The cytochemical demonstration of G6PDH activity in oocytes which had been frozen-thawed once resulted in a number of strongly stained cells and a number of cells without any formazan content. These unstained oocytes appeared to react without any noticeable loss of activity after being incorporated in a polyacrylamide matrix. This suggests strongly that freezing and thawing, as is commonly used in biochemical studies does not always make enzymes accessible for substrates and/or coenzymes. Apparently, the polymerization procedure itself enhances permeability of the cells for enzyme cytochemical studies.

Van Noorden et al. (1983) have demonstrated that data obtained cytophotometrically for G6PDH activity in different types of cells could be converted into absolute units of G6PDH activity, which showed a high correlation with data obtained biochemically from the same cells. In the present study, the relationship between data obtained cytochemically and biochemically for 6 different enzymes showed a good correlation (Text-fig. 2). The validity of the quantitative 
cytochemical method for GPI activity as described in this paper, is demonstrated in Text-fig. 1. The Dixon plot has been calculated from the readings in arbitrary units of integrated absorbance at $534 \mathrm{~nm}$ and it shows that 6-phosphogluconate is a competitive inhibitor. This is in agreement with biochemical data in homogenates (Rose \& Rose, 1969). The $K_{\mathrm{m}}$ for fructose 6-phosphate, $0.25 \mathrm{mM}$, is an order of magnitude similar to that obtained in biochemical studies of rabbit muscle for which a $K_{\mathrm{m}}=0.31 \mathrm{mM}$ was calculated (Dyson \& Noltmann, 1968). However, the calculated $K_{\mathrm{i}}(4.6 \mathrm{mM})$ was higher than the $0.16 \mathrm{~mm}$ reported for 6-phosphogluconate (Dyson \& Noltmann, 1968). An explanation for this discrepancy could not be found.

The activity of G6PDH, LDH and, to a lesser extent, GPI appeared to be extremely high in preovulatory oocytes (Table 2). LDH activity, as determined biochemically in the presence of lactate as substrate, is about $10 \%$ of the activity in the presence of pyruvate as substrate at the $\mathrm{pH}$ of the incubation medium used in this study $(\mathrm{pH}=7 \cdot 4)$. However, this lower value does correlate very well with the activity determined cytochemically. The reason for the high activity of G6PDH in oocytes is uncertain. G6PDH, the key enzyme of the pentose phosphate pathway, produces NADPH which is critical for synthetic processes, particularly fat synthesis. A second function of G6PDH is probably the formation of ribose and deoxyribose for the synthesis of RNA and DNA (Brinster, 1965a). However, the activity of 6PGDH, the next dehydrogenase in the pentose phosphate pathway, is only $2 \%$ of that of G6PDH activity. This is in agreement with the findings of Brinster (1966). Whether this low enzyme activity is able to synthesize sufficient ribose from glucose 6-phosphate for the synthesis of RNA in growing oocytes is unknown. It would be of great interest to know whether 6PGDH activity is as low in growing oocytes as it is in preovulatory oocytes, or whether the activity is higher at that stage, declining during maturation. In-vitro experiments attempting to explain the high activity of G6PDH in preovulatory oocytes are now in progress.

Van Noorden (1984) gave evidence of the validity of the method for quantification of G6PDH activity as demonstrated cytochemically. The validity has been confirmed in this study, not only for G6PDH activity, but also for the activity of other enzymes involved in carbohydrate metabolism. Therefore, the use of the methods as described in this paper widen the possibilities of studying metabolism in single oocytes, especially with respect to species in which only one or a few eggs are ovulated in one cycle.

We thank Professor Dr J. James for critical reading of the manuscript; Mrs M. Stam for typing the text; and Mr R. Lutgerhorst for drawing the figures and preparing the photomicrographs.

\section{References}

Beutler, E. (1971) Red cell metabolism. In A Manual of Biochemical Methods, pp. 50 and 62. Grune and Stratton, New York.

Brinster, R.L. (1965a) Studies on the development of mouse embryos in vitro. II. The effect of energy source. J. exp. Zool. 158, 59-68.

Brinster, R.L. (1965b) Lactate dehydrogenase activity in the preimplantation mouse embryo. Biochim. Biophys. Acta 110, 439-441.

Brinster, R.L. (1966) Glucose-6-phosphate dehydrogenase activity in the preimplantation mouse embryo. Biochem. J. 101, 161-163.

De Schepper, G.G., Van Noorden, C.J.F., Tas, J. \& James, J. (1982) Cytochemical determination of glucose-6-phosphate dehydrogenase (G6PDH) activity in mouse oocytes with the use of a polyacrylamide carrier. Cell Biol. Int. Rep. 6, 651.

De Schepper, G.G., Van Noorden, C.J.F. \& James, J.
(1984) Cytochemical determination of glucose 6phosphate dehydrogenase activity in isolated mouse oocytes. Acta histochem., Suppl. 29, 149-153.

Donahue, R.P. \& Stern, S. (1968) Follicular cell support of oocyte maturation: production of pyruvate in vitro. J. Reprod. Fert. 17, 395-398.

Dyson, J.E.D. \& Noltmann, E.A. (1968) The effect of $\mathrm{pH}$ and temperature on the kinetic parameters of phosphoglucose isomerase. J. biol. Chem. 243, 14011414.

Epstein, C.J. (1975) Gene expression and macromolecular synthesis during preimplantation embryonic development. Biol. Reprod. 12, 82-105.

James, J., Tas, J., Bosch, K.S., De Meere, A.J.P. \& Schuyt, H.C. (1979) Growth patterns of rat hepatocytes during postnatal development. Eur. J. Cell Biol. 19, 222-226.

Mangia, F. \& Epstein, C.J. (1975) Biochemical studies of Downloaded from Bioscientifica.com at 04/26/2023 01:08:41PM via free access 
growing mouse oocytes: Preparation of oocytes and analysis of glucose-6-phosphate dehydrogenase and lactate dehydrogenase activities. Devl Biol. 40, 52-58.

Rose, I.A. \& Rose, Z.B. (1969) In Comprehensive Biochemistry; Vol. 17: Carbohydrate Metabolism, pp. 104-106. Eds M. Florkin \& E. H. Stotz. Elsevier, Amsterdam.

Stuart, J., Gordon, P.A. \& Lee, T.R. (1975) Enzyme cytochemistry of blood and marrow cells. Histochem. J. 7, 471-487.

Van Noorden, C.J.F. (1984) Histochemistry and cytochemistry of glucose-6-phosphate dehydrogenase. Prog. Histochem. Cytochem. 15, 1-85.

Van Noorden, C.J.F. \& Tas, J. (1980) Quantitative aspects of the cytochemical demonstration of glucose-6-phosphate dehydrogenase with tetranitro BT studied in a model system of polyacrylamide films. Histochem. J. 12, 669-685.

Van Noorden, C.J.F. \& Tas, J. (1982a) The role of exogenous electron carriers in NAD(P)-dependent dehydrogenase cytochemistry studied in vitro and with a model system of polyacrylamide film. $J$. Histochem. Cytochem. 30, 12-20.

Van Noorden, C.J.F. \& Tas, J. (1982b) Advantages of 1methoxy PMS as electron carrier in dehydrogenase cytochemistry. Histochem. J. 14, 837-845.

Van Noorden, C.J.F., Tas, J., Vogels, I.M.C. \& De Schepper, G.G. (1982) A new method for the enzyme cytochemical staining of individual cells with the use of a polyacrylamide carrier. Histochemistry 74, 171181.

Van Noorden, C.J.F., Tas, J. \& Vogels, I.M.C. (1983) Cytophotometry of glucose-6-phosphate dehydrogenase activity in individual cells. Histochem. J. 15, 583599.

Yasumasu, I., Fujiwara, A., Shoger, R.L. \& Asami, K. (1975) Distribution of some enzymes concerning carbohydrate metabolism in sea urchin eggs. Expl Cell Res. 92, 444-450.

Received 17 December 1984 